\title{
Kadınların kişisel bakımlarının değerlendirilmesi
}

\author{
Evaluation of women's personal care
}

Melis Gönülal, Aylin Öztürk Meral, Meltem Türkmen

Gönderilme tarihi: 08.08.2019

Kabul tarihi: 27.12 .2019

Özet

Amaç: İnsanların kendilerini iyi hissetmelerini sağlayan başlıca faktörlerden biri cilt sağlığını korumak ve geliştirmektir. İnsanlara, sağlıklı cildin devamını sağlayabilmek için çeşitli ürün gamına sahip bu sektörde kendileri için en uygun ürünleri kullanmak cazip gelmektedir. Çalışmamızda toplumumuzun deri bakım ürünü kullanma alışkanlıklarını ve yaşlanma karşıtı amacıyla uyguladıkları yöntemleri incelemeyi amaçladık.

Gereç ve yöntem: Mayıs-Temmuz 2019 tarihleri arasında Sağlık Bilimleri Üniversitesi İzmir Tepecik Eğitim ve Araştırma Hastanesi ve İzmir Bozyaka Eğitim ve Araştırma Hastanesi Dermatoloji Polikliniklerine başvuran kadın hastalar çalışma grubumuza dâhil edildi. Katıımcılara kendilerine ait demografik özellikler, deri bakımı ve yaşlanma karşıtı önlemlere dair sorular içeren bir anket formu dolduruldu.

Bulgular: Çalışmamıza 200 kadın katılımcı alındı. Yaşın ilerlemesi ile gözeneklerin ve telenjiektazilerin belirginliğinin artması, omuzlarda leke oluşumu ve gıda takviyesi kullanma miktarları arasında pozitif yönlü anlamlı ilişki tespit edildi (sırayla $p \leq 0,0001, p=0,002, p=0,018, p=0,001$ ). Sigara içimiyle omuzlarda leke oluşumu arasında pozitif yönlü ilişki mevcuttu $(p=0,005)$. Güneş koruyucu krem kullanımı ile telenjiektazi varlığı ve gözenek belirginliği arasında pozitif yönlü ilişki (sırayla $p=0,008, p \leq 0,0001$ ) bulundu; ama güneş koruyucu kullanımı ile yüzde, el-kol bölgesinde ve omuzlarda leke oluşumu arasında anlamlı bir ilişki mevcut değildi (sırayla $p=0,2, p=0,69, p=0,11$ ).

Sonuç: Çalışmamız kadınların cilt bakımları hakkındaki yönelimlerini tespit etmesi ve değişkenler arasındaki ilişkileri de incelemesi bakımından bu alanda literatüre değer katmaktadır, çünkü bu alanda yapılan çalışmaların çoğunluğu tanımlayıcı niteliktedir. İlerde daha büyük gruplarda yapılabilecek çalışmalar ve toplum yaşam standartlarındaki değişimler daha farklı sonuçlar çıkmasını sağlayabilir ama bu şekliyle çalışmamızın günümüz koşullarını yansıtması ve bu alanda yetersiz sayıda çalışma olmasından dolayı literatüre katkı sağlayabileceğini düşünüyoruz.

Anahtar kelimeler: Cilt, gözenek, telenjiektazi, güneş koruyucu, nemlendirici.

Gönülal M, Öztürk Meral A, Türkmen M. Kadınların kişisel bakımlarının değerlendirilmesi. Pam Tıp Derg 2020;13:169-175.

\begin{abstract}
Purpose: One of the most important factors that feel people themself good is to protect skin health and make it better. People like to use the most appropriate products that can protect and develop their skins' qualities. In our study we aimed to evaluate women how to use products for dermocosmetics and modalities for antiaging. Materials and methods: Women who applied to the out-patient dermatology clinic of University of Health Sciences, İzmir Tepecik Training and Research Hospital and İzmir Bozyaka Training and Research Hospital between May-July 2019, were included. A survey form that contained questions about demographic features, skin care and anti-aging methods was filled by the participants.

Results: There were 200 women as participants in our study. There was a positive significant correlation between age and pore specificity, telangiectasia, spots on shoulders, food supplement (in order $p \leq 0,0001 p=0,002$ $p=0,018 p=0,001)$. We detected a positive significant correlation between smoking and spots on shoulders $(p=0,005)$. We found a positive significant correlation between creaming sunscreen and telangiectasia, pore specificity (in order $p=0,008 p \leq 0,0001$ ) but there was no significant correlation between creaming sunscreen and spots on face, hand-arm, shoulders (in order $p=0,2 p=0,69 p=0,11$ ).

Conclusion: Our study that determines tendencies about skin care of women and relationships between variebles, may add value to literature. Further, studies in larger groups and changes in community life standars may set for the more different results but we believe that because our study can reflect current conditions and there are few studies about this topic, our study can contribute to literature.
\end{abstract}

Key words: Skin, pore, telangiectasia, sunscreen, moisturizer.

Melis Gönülal, Uzm. Dr. İzmir Tepecik Eğitim ve Araştırma Hastanesi, Dermotoloji Kliniği, Onkoloji Binası, Bornova/IZMiR, e-posta: drmelis@ gmail.com (orcid.org/0000-0002-6042-656X) (Sorumlu Yazar)

Aylin Öztürk Meral, Uzm. Dr. İzmir Tepecik Eğitim ve Araştırma Hastanesi, Dermotoloji Kliniği, Onkoloji Binası, Bornova/IZMiR, e- posta: draylinnew@yahoo.com (orcid.org/0000-0001-9224-0252)

Meltem Türkmen, Uzm. Dr. İzmir Bozyaka Eğitim ve Araştırma Hastanesi, Dermotoloji Kliniği, Karabağlar/IZMiR, e-posta: meltemturkmen@ hotmail.com (orcid.org/0000-0003-1216-2253) 
Gönülal M, Öztürk Meral A, Türkmen M. Evaluation of women’s personal care. Pam Med J 2020;13:169-175.

\section{Giriş}

Dermatoloji sadece hastalıklı deriyle ve deri ekleriyle değil, sağlıklı deri ve ekleriyle de ilgilenen ve tedaviler sunan bir bilim dalıdır [1]. Kozmetik sektöründeki seçeneklerin artması, tedavi şekillerinin çeşitlenmesi, sosyal medya ile diğer görsel ve yazılı basının etkisiyle kadınların kozmetik ürünlerinin kullanmadaki alışkanlıkları da zamanla değişime uğramıştır. İlginç olanı geçmişe bakacak olursak kozmetik ürünlerin kullanımı savaşlardan ve ekonomik koşullardan pek etkilenmemiştir, insanlar kişisel bakımlarının her daim olabildiğince en iyi şekilde devam etmesine özen göstermişlerdir [2].

Kozmetik ürünler, deriye, saçlara, kıllara, müköz membranlara, dişlere uygulanabilen, tedavi amacı olmayan maddelerdir. Günümüzde kozmetik sektörü oldukça gelişmiş ve her sosyoekonomik kesime hitap edebiliyor olması nedeniyle her evde en az bir adet kozmetik ürüne rastlanabilmektedir [3]. İnsanlara, sağlıklı cildin devamını sağlayabilmek için çeşitli ürün gamına sahip bu sektörde kendileri için en uygun ürünleri kullanmak cazip gelmektedir [2].

Cildin sağlığını korumak ve geliştirmek amacıyla çeşitli kozmetik ürünlerin kullanımının yanı sıra bazı ekstrensek faktörlere de kadınlar arasında dikkat edilmektedir, çünkü deri sağlığı ve güzelliği, insanların kendilerini iyi hissetmelerini sağlayan başlıca faktörlerden biridir [4].

Ülkemizde kadınlar arasında kişisel bakım rutinlerini değerlendiren çok az sayıda çalışma mevcuttur. Çalışmamızda toplumumuzun deri bakım ürünü kullanma alışkanlıklarını ve yaşlanma karşıtı amacıyla uyguladıkları yöntemleri incelemeyi amaçladık.

\section{Gereç ve yöntem}

Mayıs 2019- Temmuz 2019 tarihleri arasında Sağlık Bilimleri Üniversitesi İzmir Tepecik Eğitim ve Araştırma Hastanesi ve İzmir Bozyaka Eğitim ve Araştırma Hastanesi Dermatoloji Polikliniklerine başvuran kadın hastalar çalışma grubumuza dâhil edildi. Çalışmamıza yaygın deri hastalığı olanlar, ağır sistemik hastalığı olanlar, 18 yaş altı ve 70 yaş üzeri kişiler dâhil edilmedi. Tüm katılımcıların onamları alındıktan sonra kendilerine ait demografik özellikler, deri bakımı ve yaşlanma karşıtı önlemlere dair sorular içeren bir anket formu dolduruldu. Katılımcıların yaş, boy, kilo, sigara-alkol kullanma durumu, Fitzpatrick deri tipleri, lekelenme (yüz, el-kol, omuz), yüzde telenjiektazi ve gözenek varlığı (hastaların her iki yanak bölgesi incelenerek), yüz bakım kremi, göz bakım kremi, vücut bakım kremi, güneş koruyucu krem kullanım alışkanlıkları, güneş koruyucuları kaç saatte bir sürdükleri, güneşlenme alışkanlıkları, kaç saat süreyle güneşlendikleri, makyaj yapma, gıda takviyesi kullanma, kullanıyorsa ne içerikte olduğu, daha önceden izotretinoin tedavisi alma durumları not edildi. Gözenek ve telenjiektazi belirginliğini gözlemleyebilmek amacıyla Dermlite marka DL200HR model dermatoskop kullanıldı. Çalışmamız için etik kurul onayı Sağlık Bilimleri Üniversitesi, İzmir Tepecik Eğitim ve Araştırma Hastanesi Etik Kurulu tarafından alınmıştır.

Tüm istatistiksel yöntemler SPSS 17 kullanılarak yapıldı. Çeşitli değişkenlerin normal dağılıma uygun olup olmadığı saptandı (Kolmogorov-Smirnov/Shapiro-Wilk testleri). İstatistiksel analizlerde Spearman ve Kikare korelasyon testleri kullanıldı. $p<0,05$ altı sonuçlar istatistiksel olarak anlamlı kabul edildi.

\section{Bulgular}

Çalışmamıza 200 kadın katılımcı alındı. Yaş ortalaması $38,15 \pm 10,11$ olarak tespit edildi. Boy ortalaması $163,75 \pm 5,29$ ve kilo ortalaması $62,64 \pm 10,93$ olarak bulundu. Sigara içen kişi sayısı 46 (\%23), alkol içen kişi sayısı $5(\% 2,5)$ 'ti. Fitzpatrick deri tipi 1 olan $33(\% 16,5)$, deri tipi 2 olan $95(\% 47,5)$, deri tipi 3 olan 68 (\%34) ve 4 olan 4 kişi (\%2) vardı. Yüzünde lekeler olan 50 kişi (\%25), el-kol bölgesinde lekelenme olan 16 kişi (\%8), omuzlarda lekeleri olan 30 kişi (\%15) mevcuttu. Yüz dört kişinin yanaklarında gözenekler belirgin (\%52) ve 93 kişinin yanaklarında telenjiektazi $(\% 46,5)$ vardı. 65 kişinin $(\% 32,5)$ yanaklarında hem gözenekler belirgin hem de telenjiektazi tespit edildi (Tablo 1). Herhangi bir yüz bakım kremini her gün süren 93 kişi $(\% 46,5)$, haftada 2 ila 6 gün arası kullanan 34 kişi (\%17), haftada bir kez süren 3 kişi (\%1,5), hiç kullanmayan 70 kişi (\%35), herhangi bir göz çevresi bakım kremi kremini 
her gün kullanan 67 kişi $(\% 33,5)$, haftada 2 ila 6 gün arası kullanan 28 kişi (\%14), haftada bir kez süren $3(\% 1,5)$ ve hiç kullanmayan 102 kişi (\%51), herhangi bir vücut bakım kremini her gün süren 13 kişi $(\% 6,5)$, sadece banyo sonrası kullanan 66 kişi (\%33), sadece kuruluk olunca kullanan 53 kişi $(\% 26,5)$ ve hiç kullanmayan 68 kişi (\%34), güneş koruyucu kremi sadece yazın kullanan 62 kişi (\%31), tüm mevsimler kullanan 69 kişi $(\% 34,5)$ ve hiç kullanmayan 69 kişi $(\% 34,5)$ mevcuttu. Güneş koruyucu kremi 5 saatten az süren 38 kişi (\%19), 5 saatten fazla süre geçince tekrar kullanan $93(\% 46,5)$ kişi bulundu (Tablo 2). Güneş koruyucu kremi yüze süren 130 kişi (\%65), boyuna süren 52 kişi (\%26), el-kol için kullanan 21 kişi $(\% 10,5)$, bacaklara süren 4 kişi (\%2) mevcuttu (Tablo 3). Güneşlenme alışkanlığı olan 60 katılımcı (\%30) olduğu saptandı, bu kişilerin 47 tanesinin 2 saatten az $(\% 23,5), 13$ tanesinin $(\% 6,5) 2$ saatten fazla süreyle güneşlendiği bulundu. Gıda takviyesi kullanan 25 kişi $(\% 12,5)$ vardı, 9 tanesi omega3, 5 tanesi Q10, 1 tanesi antioksidan içerikli ismini hatırlamadığı bir ürün, 7 tanesi vitamin, 1 tanesi soya lesitini, 2 tanesi beta glukan ile c vitamini kullanıyordu. Makyaj yapan katılımcılardan (148 kişi) 4 tanesi sadece işyerinde (\%2), 32 tanesi sosyal yaşamda (\%16) ve 112 tanesi (\%56) hem iş yerinde hem de sosyal yaşamda makyajlarını yapıyorlardı. Daha önceden izotretinoin tedavisi almış kişi sayısı $9(\% 4,5)$ olarak bulundu.

Tablo 1. Lekelenme, gözenek, telenjiektazi üzerine veriler.

\begin{tabular}{lcccc}
\hline & Var $(\mathbf{n})$ & $\%$ & Yok $(\mathbf{n})$ & $\%$ \\
\hline Yüz lekelenme & 50 & 25 & 150 & 75 \\
El-kol lekelenme & 16 & 8 & 184 & 92 \\
Omuz lekelenme & 30 & 15 & 170 & 85 \\
Gözenek & 104 & 52 & 96 & 48 \\
Telenjiektazi & 93 & 46,5 & 107 & 53,5 \\
\hline
\end{tabular}

Tablo 2. Kişisel bakım kremlerinin kullanım şekilleri.

\begin{tabular}{|c|c|c|}
\hline & Sayı (n) & Yüzde (\%) \\
\hline \multicolumn{3}{|l|}{ Yüz kremi } \\
\hline Her gün & 93 & 46,5 \\
\hline Haftada 2-6 & 34 & 17 \\
\hline Haftada bir & 3 & 1,5 \\
\hline Hiç & 70 & 35 \\
\hline \multicolumn{3}{|l|}{ Göz çevresi kremi } \\
\hline Her gün & 67 & 33,5 \\
\hline Haftada 2-6 & 28 & 14 \\
\hline Haftada bir & 3 & 1,5 \\
\hline Hiç & 102 & 51 \\
\hline \multicolumn{3}{|l|}{ Vücut kremi } \\
\hline Her gün & 13 & 6,5 \\
\hline Banyo sonrası & 66 & 33 \\
\hline Kuruluk olunca & 53 & 26,5 \\
\hline Hiç & 68 & 34 \\
\hline \multicolumn{3}{|c|}{ Güneş koruyucu krem } \\
\hline Her mevsim & 62 & 31 \\
\hline Sadece yaz & 69 & 34,5 \\
\hline Hiç & 69 & 34,5 \\
\hline
\end{tabular}


Tablo 3. Güneş koruyucu krem kullanım alışkanlığı.

\begin{tabular}{lll}
\hline & Sayı (n) & Yüzde(\%) \\
\hline Yüz & 130 & 65 \\
Boyun & 52 & 26 \\
El-kol & 21 & 0,5 \\
Bacak & 4 & 2 \\
Yüz ve boyun & 18 & 9 \\
Yüz ve el-kol & 1 & 0,5 \\
Yüz, boyun, el-kol & 9 & 4,5 \\
Yüz, boyun, el-kol, bacak & 2 & 1 \\
Hiç & 69 & 34,5 \\
\hline
\end{tabular}

Tablo 4. Fitzpatrick deri tipi, yüz kremi, güneş koruyucu, sigara ve alkol kullanımının çeşitli değişkenler üzerine etkileri.

\begin{tabular}{lllllll}
\hline $\boldsymbol{p}$ & Gözenek & Telenjiektazi & Yüz leke & El-kol leke & Omuz leke & Gıda takviyesi \\
\hline Fitzpatrick & 0,17 & 0,096 & $\mathbf{0 , 0 0 2}$ & 0,18 & 0,39 & 0,7 \\
Yüz kremi & $\leq \mathbf{0 , 0 0 0 1}$ & 0,11 & 0,33 & - & - & 0,13 \\
Güneş koruyucu & $\mathbf{\leq 0 , 0 0 0 1}$ & $\mathbf{0 , 0 0 8}$ & 0,2 & 0,69 & 0,11 & $\mathbf{0 , 0 1 8}$ \\
Sigara & 0,3 & 0,12 & 0,088 & 0,41 & $\mathbf{0 , 0 1 6}$ & 0,71 \\
Alkol & 0,2 & 0,54 & 0,43 & 0,31 & 0,11 & 0,86 \\
Yaş & $\leq \mathbf{0 , 0 0 0 1}$ & $\mathbf{0 , 0 0 2}$ & 0,085 & 0,75 & $\mathbf{0 , 0 1 8}$ & $\mathbf{0 , 0 0 1}$ \\
\hline
\end{tabular}

Fitzpatrick deri tipi ile gözeneklerin belirginliği ve telenjiektazi varlığı arasında anlamlı bir ilişki bulunmadı (sırayla $p=0,17, p=0,96$ ). Sigara kullanımı ile omuzlarda leke oluşumu arasında pozitif yönlü anlamlı ilişki tespit edildi $(p=0,016)$. Yüz kremi kullanım alışkanlığı ile telenjiektazi varlığı arasında anlamlı bir ilişki tespit edilmedi $(p=0,116)$ ama gözenek belirginliği ile arasında anlamlı bir ilişki görüldü $(p \leq 0,0001)$. Yüz kremi kullanım alışkanlığı ile makyaj yapımı, daha önceden izotretinoin kullanımı ve güneş koruyucu krem sürme alışkanlığı arasında pozitif yönde ilişki mevcuttu (sırayla $p \leq 0,0001, p=0,016, p \leq 0,0001)$. Yüz ve boyuna güneş koruyucu krem sürümü ile yüz kremi, göz çevresi kremi ve vücut kremi kullanımı arasında pozitif yönde ilişki bulundu (her üçü için de $p \leq 0,0001)$. Göz çevresi kremi kullanım alışkanlığı ile izotretinoin kullanım geçmişinin olması arasında pozitif yönlü anlamlı ilişki vardı $(p=0,048)$ ama gıda takviyesi kullanımı ile anlamlı ilişki tespit edilemedi $(p=0,53)$. Vücut kremi kullanım alışkanlığı ile sigara kullanımı ve gıda takviyesi alımı arasında pozitif yönlü ilişki mevcuttu (sırayla $p=0,018, p=0,001$ ). Güneş koruyucu krem kullanımı ile telenjiektazi varlığı, gözenek belirginliği, gıda takviyesi kullanımı ve güneşlenme süresi arasında pozitif yönlü ilişki (sırayla $p=0,008, p \leq 0,0001, p=0,045, p=0,024$ ) bulundu ama güneş koruyucu kullanımı ile yüzde, el-kol bölgesinde ve omuzlarda leke oluşumu arasında anlamlı bir ilişki mevcut değildi (sırayla $p=0,2, p=0,69, p=0,11$ ). Güneş koruyucu kullanımı ile sigara tüketimi arasında anlamlı bir ilişki bulunmadı ama alkol kullanımı ile arasında pozitif yönlü bir ilişki tespit edildi (sırayla $p=0,98, p=0,05$ ). Sigara içimi ile omuzlarda leke oluşumu ve güneşlenme süresi arasında pozitif yönlü ilişki mevcuttu (sırayla $p=0,16, p=0,005$ ) ama sigara içimi ile gözenek belirginliği ve telenjiektazi varlığı arasında anlamlı bir ilişki tespit edilmedi (sırasıyla $p=0,3$, $p=0,12$ ). Alkol kullanımı ile gözenek belirginliği ve telenjiektazi varlığı arasında anlamlı ilişki bulunmadı (sırayla $p=0,2, p=0,54$ ). Güneşlenme süresi ile gıda takviyesi alımı arasında pozitif yönlü anlamlı ilişki bulundu $(p=0,045)$. Yaşın ilerlemesi ile gözeneklerin ve telenjiektazilerin belirginliğinin artması, omuzlarda leke oluşumu ve gıda takviyesi kullanma miktarları arasıda pozitif yönlü anlamlı ilişki tespit edildi (sırayla $p \leq 0,0001, p=0,002, p=0,018, p=0,001)$, yaşın 
ilerlemesi ile yüzde ve el-kol bölgesinde leke oluşumu arasında anlamlılık bulunmadı (sırasıyla $p=0,085, p=0,75$ ).

\section{Tartışma}

Ülkemizde kadınların deri bakımı ve yaşlanma karşıtı önlemler üzerine bilgilerini inceleyen çalışma sayısı sınırlıdır. Deri bakımı, kozmetik ürünler ve yaşlanma karşıtı ürünler insanın moral motivasyonunu arttıran faktörlerdir [5]. Sigara içme oranı çalışmamızda katılımcıların beşte birine yakındı, beşte dört kadın katılımcı sigara kullanmıyordu. Sigara inflamatuar yanıtları direk uyarabilen bir maddedir, yaşlanma sürecini hızlandırır dolayısıyla sigara kullanmamak yaşlanma karşıtı alınabilecek en basit tedbirlerden biridir [6].

Çalışmamızda yaş ortalaması $38,15 \pm 10,11$ olmasına rağmen yani genç bir popülasyon olmasına rağmen yanaklarda gözenek belirginliğinin \%52 ve telenjiektazi varlığının \%32,5 olması çalışma grubuna katılanların deri bakımlarını istenildiği düzeyde yapmadıklarını, yaşlanma karşıtı önlemleri alamadıklarını ortaya koyuyordu. Yüz bakım kremini hiç kullanmayan \%35 kişi ve göz çevresi bakım kremini kullanmayan \%51'di, bu veriler kişilerin sosyoekonomik durumlarına, aylık gelirlerine ve bu alanla ilgili bilgilerinin kısıtlı olmasına bağlı olabilir. Gökdemir ve ark. [2] çalışmasında nemlendirici kullanma durumu sorgulanmıştır, kullanım oranı tüm katılımcılar arasında \%37,9 olarak bulunmuştur, yalnız bu çalışmada nemlendirici kullanımı kategorize edilmemiş ve erkek katılımcılar da çalışmaya dahil edilmiştir. Daye ve ark.'nın [5] çalışmasında nemlendirici kullanım oranı her gün kategorisinde (günde bir, günde iki, günde üç olarak kayıt edilmiştir) \%54,3'tür, kuruluk hissedince nemlendirici kullanan kişilerin oranı \%45,6 olarak bulunmuştur.

Çalışmamızda güneş koruyucuları tüm mevsimler kullanan kişi sayısı, sadece yazın kullananlardan bir miktar daha fazlaydı, bunun nedeninin kişilerin güneşin zararlı etkileri hakkında daha fazla bilgi sahibi olmaya ve dış görünüşlerine daha fazla önem vermeye başlamaları, güneş koruyucu ürün gamında zamanla oluşan artışın ulaşılabilirlik oranını da arttırması olduğunu düşünüyoruz. Güneş koruyucu kullanmayan kişi oranının \%34,5 olduğunu da göz önüne alırsak sonuçlar tam da istenildiği gibi değildir. Güneş koruyucu kremler güneşin zararlı etkilerini önlemede kullanılan stratejilerin en önde gelenlerinden biridir ve bu konuda insanların bilgileri her geçen gün daha da artmaktadır [1]. Çınar ve ark. [7] hemşirelik yüksek okulunda yaptıkları çalışmalarında güneş koruyucu kullanım oranını $\% 78,1$, sadece yazın kullananlar \%43,5, yaz-kış kullananlar \%9 tespit etmişlerdir. İlter ve ark.'nın [8] çalışmasında genel popülasyonun güneşin zararlı etkileri ve etkin korunma yöntemleri konusunda bilinçli olmadığı gösterilmiş ve güneşin etkileri konusunda bilinçlendirme kampanyalarının aktif olarak planlanması gerekliliği ortaya koyulmuştur.

Güneşlenme oranı çalışmamızda \%30 olarak bulunmuştur, her üç kişiden birinin güneşlenmeyi tercih etmesi güneşin zararlı etkilerinin tam da anlaşılmadığını ortaya koymaktadır. Kaptanoğlu ve ark.'nın [9] çalışmasında katılımcıların \%44,5'unun güneşten korunma konusundaki bilgileri öncelikle televizyondan, dergi ve gazetelerden öğrendikleri tespit edilmiştir. Basın yayın araçlarının bu konuda daha etkin rol alması gerektiğini düşünüyoruz.

Besin destek ürünleri; (gıda takviyeleri, supleman ya da beslenme desteği olarak da sıklıkla kullanılmaktadır) vitamin ve minerallerin yüksek dozlara karşılık gelen miktarlarının hap, kapsül, şurup şeklinde kullanılabilir formları olarak tanımlanmakta ve beslenmede yer alan besinlere ek anlamına gelmektedir. Besin destekleri genel olarak; vitaminler, mineraller, aminoasitler, esansiyel yağ asitleri, posa, çeşitli bitkiler ve bunların ekstrelerini de kapsayan geniş bir yelpazeye sahiptir [10]. Gıda takviyesi kullanım oranı çalışmamızda katılımcılar arasında \%12,5 bulundu, düşük olmasının nedenini kişilerin gıda takviyeleri hakkında ön yargılı olabileceğine, sosyoekonomik durumlarının ve aylık kazançlarının elverişli olamamasına bağladık. Başka bir çalışmada Türkiye'de gıda takviyesi kullanım oranı \%13 bulunmuştur, ön planda olan tüketim ürünü vitamin-mineral grubudur. Bu çalışmanın sonuçlarına göre gıda takviyesi kullanım oranının düşük olmasındaki neden katılımcıların ürünlere yönelik genel bir kafa karışıklığının olması ve ürünlere güvenmemeleridir. Ek olarak denetim ve standartlar konusunda da ilgili bakanlıkların yeterli düzeyde sürece müdahil olmadıkları katılımcılar tarafından düşünülmektedir [11]. 
Makyaj toplumda önemli bir yere sahiptir. İki kişinin karşılaşmasında makyajı yapan ile karşısındaki kişi arasında görsel yolla en etkili iletişim kurulmuş olur ve bu iletişim konuşma ile kurulacak iletişimden daha etkilidir [12]. Çalışmamızda hem iş yerinde hem de sosyal yaşamda makyaj yapanların oranını \%56 olarak bulduk, katılımcıların yarısının dış görünüşlerine dikkat etmelerini onların bu konudaki hassasiyetine, sosyokültürel olarak buna gereklilik duymalarına ve aylık kazançları gereği makyaj ürünlerine kolaylıkla ulaşabilir olduklarına bağladık.

Çalışmamı sonuçlarına göre kişinin Fitzpatrick deri tipi gözenek ve telenjiektazi oluşumları üzerinde etkin değildir ama yüzde leke oluşumunda etkin bir faktördür. $\mathrm{Bu}$ sonuçlara göre gözenek ve telenjiektazi oluşumda dış etkenlerin, leke oluşumunda genetik faktörlerin daha etkin olduğunu düşünüyoruz. Yüz kremlerini düzenli kullanmak gözenek belirginliğini azaltabilir ama telenjiektazi oluşumunu önleyemez, bu nedenle lekeli cilt yapısına sahip kişilerin leke önleyici özelliği olan yüz bakım kremlerini, telenjiektaziye eğilimli kişilerin telenjiektaziyi önleyici kremleri kullanmaları gerektiğine inanıyoruz. Yüz kremlerini düzenli kullanan kişilerin dış görünüşlerine de önem verdikleri ve güneşin zararlı etkilerinden optimum düzeyde korunmak istedikleri gözlemlendi. Güneş koruyucu kremlerin telenjiektazi ve gözenek oluşumunu azaltabileceği saptandı. Yaşlanma karşıtı etkisi olan güneş koruyucuları kullananların ek olarak yaşlanma karşıtı gıda takviyesi kullanmaya eğilimlerinin olduğu belirlendi. Bu sonuca göre kadınların imkanları dâhilinde yaşlanma karşıtı önlemleri en iyi seviyede almak istediklerini düşünüyoruz. Güneş koruyucuların yüz, el-kol bölgesi ve omuzlarda leke oluşumunu önleyici etkilerinin olmadığı saptandı. Bu ilginç sonuca göre leke oluşumunda daha önce de belirtildiği gibi genetik faktörlerin daha ön planda olduğunu düşünüyoruz ek olarak leke şikayetiyle gelen hastalara önerilen güneş koruyucuların mutlaka lekeli ciltler için üretilmiş olanlarından olması gerektiğine inanıyoruz. Sigaranın gözenek ve telenjiektazi oluşturucu etkisi saptanmadı ama omuzlarda leke oluşturucu etkisinin olduğu belirlendi. Sigaranın deri yaşlanması üzerindeki etkisinin omuzlarda daha ön planda olduğunu düşünüyoruz. Yaşın ilerlemesiyle birlikte yaşlanma belirtilerinden olan gözenek genişliğinin artması ve telenjiektazilerin oluşması çalışmamızda da tespit edilmiştir. Yaşlanma ile leke oluşumunun yüz ve el-kol bölgelerinden ziyade omuzlarda daha ön planda olduğunu düşünüyoruz. Bir hastanın derisindeki yaşlanma belirtilerini görebilmek için öncelikle omuzların muayene edilmesi gerektiğine inanıyoruz. Gelişen yaşam şartları ve sosyokültürel durum gereği insanların gıda takviyelerine ulaşabilme oranları artmıştır, çalışmamızda da yaşlanma ile birlikte gıda takviyelerinin tüketim oranının arttığını belirledik (Tablo 4).

Çalışmanın kısıtlılıklarına değinecek olursak, sigara kullanımını sorgularken kişinin o anki alışkanlığını sorguladık yani geçmişe dair bırakmış kullanıcı olup olmadığını dâhil etmedik. Yüz ve gövdedeki lekelenme durumu hastanın önceden sigara içip içmemesine göre başka bir çalışmada ayrıntılı değerlendirilebilir. Yüz/gövde lekelenme durumunu var/yok olarak değerlendirdik, yaşlanma süreci içinde lekelenme durumunun klasifikasyonunun yapılabileceği içeriği daha zengin ve konuya daha odaklı çalışmalar planlanabilir. Hastaların günlük bakım kremi kullanıp kullanmamalarını var/yok şeklinde değerlendirebildik, bakım kremlerinin içeriklerinin de dahil edilebileceği daha ayrıntılı çalışmalar ilerde yapılabilir, çünkü kremlerin içerikleri de yüzdeki gözenek genişlemesi, telenjiektazi ve lekelenme durumuna etki edebilecektir. Yine aynı şekilde güneş koruyucularının kullanım durumunu var/yok olarak değerlendirebildik, güneş koruyucularının içeriklerinin de dahil edilebileceği ve ciltteki yaşlanma sürecine etkilerinin incelenebileceği daha ayrıntılı çalışmalar planlanabilir.

Çalışmamı kadınların cilt bakımları hakkındaki yönelimlerini tespit etmesi ve değişkenler arasındaki ilişkileri de incelemesi bakımından bu alanda literatüre değer katmaktadır, çünkü bu alanda yapılan çalışmaların çoğunluğu tanımlayıcı niteliktedir. İlerde daha büyük gruplarda yapılabilecek çalışmalar ve toplum yaşam standartlarındaki değişimler daha farklı sonuçlar çıkmasını sağlayabilir ama bu şekliyle çalışmamızın günümüz koşullarını yansıtması ve bu alanda yetersiz sayıda çalışma olmasından dolayı literatüre katkı sağlayabileceğini düşünüyoruz.

Çıkar ilişkisi: Yazarlar çıkar ilişkisi olmadığını beyan ederler. 


\section{Kaynaklar}

1. Wallach D. The field of cosmetic dermatology: the need for a patient-centred approach. J Cosmet Dermatol 2002;1:137-141. https://doi.org/10.1046/ j.1473-2165.2002.00042.x

2. Gökdemir G, Arı $S$, Köşlü A. Türk toplumunda deri bakımı ile ilgili bilgi seviyesinin değerlendirilmesi. Turkderm 2008;42:60-63.

3. Kaymak Y, Çelik B, Şimşek I. Aynı fakültenin farklı bölümlerinde okuyan kız öğrencilerde kozmetik ürün kullanımı. Türk Dermatoloji Dergisi 2007;1:38-42.

4. Ganceviciene R, Liakou Al, Theodoridis A, Makrantonaki E, Zouboulis CC. Skin anti-aging strategies. Dermatoendocrinol 2012;4:308-319. https:// doi.org/10.4161/derm.22804

5. Daye M, Mevlitoğlu İ, Şahin TK. Dermatoloji polikliniğine başvuran olguların deri bakımı ve nemlendiricilerle ilgili bilgi, tutum ve davranışlarının değerlendirilmesi. Turkderm 2015;49:60-65. https://doi.org/10.4274/ turkderm. 82346

6. Nicita-Mauro V, Basile G, Maltese G, Nicita-Mauro C, Gangemi S, Caruso C. Smoking, health and ageing. Immun Ageing 2008:5:10. https://doi. org/10.1186/1742-4933-5-10

7. Çınar FI, Çetin FŞ, Kalender N, Bağcivan G. Hemşirelik yüksekokulu öğrencilerinin güneşten korunmaya ilişkin davranışlarının belirlenmesi. Gülhane Tıp Derg 2015;57:241-246. https://doi.org/10.5455/ gulhane. 156821

8. İlter N, Öztaş MO, Adışen E, ve ark. Ankara'da bir alışveriş merkezinde yapılan nevüs taramasında popülasyonun güneşten korunma alışkanlıkları ve melanositik nevüslarının değerlendirilmesi. Turkderm 2009;43:155-159.

9. Kaptanoğlu AF, Dalkan C, Hıncal E. Kuzey Kıbrıs Türk toplumunda güneşten korunma: ilkokul çağı çocukları ve ailelerinin güneşten korunma ile ilgili bilgi, tutum ve davranışları. Turkderm 2012;46:121-129. https://doi. org/10.4274/Turkderm.08831

10. Ergen A, Bozkurt Bekoğlu F. Türkiye'de besin destek ürünlerine yönelik görüşler ve tüketici profilini tanımlamaya yönelik bir araştırma. Journal of Business Research Turk 2016;8:323-341.

11. Ipsos Sosyal Araştırmalar Enstitüsü. Available at: http://gtbd.org.tr/wp-content/ uploads $/ 2017 / 12 / \%$ C3\%B6zlem-bora-GIDATAKV\% C $4 \%$ B OYES \% C 4 \% B 0 - KULLANIMARA\%C5\%9ETIRMASI-.pdf. Erişim tarihi 01.08.2019.

12. Gündüz A. Boyanmanın toplumsal işlevi. Anadolu Üniversitesi Sanat ve Tasarım Dergisi 2016;10:147167. 